\title{
Belief in Divine Moral Authority: Validation of a Shortened Scale with Implications for Social Attitudes and Moral Cognition
}

\author{
Ain Simpson ${ }^{a}$ \\ Jared Piazza ${ }^{b}$ \\ Kimberly $\operatorname{Rios}^{\mathrm{a}}$

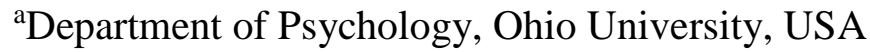 \\ ${ }^{b}$ Department of Psychology, Lancaster University, UK
}

***this is a pre-print of the manuscript accepted for publication in the journal

Personality and Individual Differences $\left(19^{\text {th }}\right.$ January, 2016), 10.1016/j.paid.2016.01.032*** 


\section{Highlights:}

- A shortened, 5-item scale measuring belief in divine moral command is established

- The scale shows good construct, convergent, and incremental validity

- Divine Command beliefs best explain religious believers' attitudes toward atheists

- Also best explain believers' propensity toward deontological/prohibitive morality

- This scale should be important in ongoing research into religious/moral psychology 


\begin{abstract}
Religion and morality have been deeply interwoven throughout human history. Although much research has investigated the role of religiosity (e.g., belief in God, prayer, religious attendance) in shaping moral concerns, only recently has research in psychology begun to delve deeper into the meta-ethical beliefs theists hold about the spiritual foundations of morality. The present research builds on moral-philosophical discourse on Divine Command Theory and recent work by Piazza and Landy (2013), who developed the 20-item Morality Founded on Divine Authority (MFDA) scale to measure Divine Command beliefs. We sought primarily to reduce the MFDA scale to increase its pragmatic utility; Confirmatory Factor Analysis revealed an optimal 5-item scale. Across four studies, this scale yielded levels of construct, convergent, and incremental validity equivalent to those of the 20 -item scale. Compared with several other measures of religiosity and conservative thinking, the short MFDA was the strongest predictor of anti-atheist prejudice among U.S. Christians and Indian Hindus (Studies 1a-1b) and largely explained religiosity's relationship with attitudes toward science (Study 1a) and moral cognitive outcomes including deontological reasoning (Study 2a) and prohibitive morality (Study 2b). We conclude with discussion about the practical utility of this scale in ongoing research into religion and moral cognition.
\end{abstract}

Key words: Religiosity, morality, moral cognition, meta-ethical beliefs, Atheism, prejudice, Divine Command Theory, Morality Founded on Divine Authority. 
"I couldn't go on living if I did not feel it with all my heart a moral structure with real meaning and forgiveness and some kind of higher power. Otherwise there is no basis to know how to live."

From Woody Allen's Crimes and Misdemeanors

Religion and morality have long been interlinked. Indeed, religion may have facilitated the rise of modern civilizations by serving to unite individuals around a set of shared beliefs, practices, and moral principles (e.g., Graham \& Haidt, 2010; Norenzayan et al., in press). Historically, religious institutions typically served as the chief sources of moral guidance and legal practice for millennia prior to the establishment of secular moral institutions such as government, police, and courts of law (Norenzayan, 2013).

This strong cultural nexus between religion and morality persists in the current era, and may serve as a source of anxiety about cultural shifts toward secular governance (Gervais, 2013). Even today amidst increasingly secular and progressive cultural developments, a common tenet among religious believers across several diverse cultures is that one cannot be moral without believing in a supernatural, higher power (e.g., $53 \%$ of U.S., $70 \%$ of Indian, and a vast majority of African, Middle Eastern, Asian, and Latin American pollees; Pew, 2014; also see Edgell, Gerteis, \& Hartmann, 2006; Gervais, 2013). For many religious believers, being a moral person depends on being religious. Understandably, therefore, religion remains a potent guide to people's deepest moral values and beliefs.

Evidence shows that religiosity shapes morally relevant attitudes and behavior in a wide variety of ways (Norenzayan et al., in press; Shariff, Piazza, \& Kramer, 2014). For example, the stronger one identifies as religious, the more likely one expresses the values of maintaining ingroup loyalties, paying deference to authority, and adhering to puritanical notions of sexual purity and decency (Piazza \& Landy, 2013). Among Western samples, the more a person 
identifies with their religion, the less willing they are to engage in utilitarian forms of moral reasoning and argumentation (Antonenko Young, Willer \& Keltner, 2013; Piazza, 2012; Piazza \& Sousa, 2013). In addition, among samples of Israelis and Palestinians participation in organized religion increased support for terrorist activities (Ginges, Hansen, \& Norenzayan, 2009). However, with the exception of a few papers (e.g., Goodwin \& Darley, 2008; Piazza \& Landy, 2013), very little research has considered how religion affects the way in which people think about the epistemic foundations of morality, that is, the "meta-ethics" of how moral truths originate and are established. If the majority of people worldwide believe that it is necessary to believe in God in order to be moral (Pew, 2014), and look to their religion to provide guidance for living morally, then this implicates beliefs about God's role in morality as a strong factor in shaping people's moral thinking.

Recently, Piazza and Landy (2013) explored this issue by establishing a 20-item measure of the belief that Morality is Founded on Divine Authority (MFDA). They found MFDA to be a powerful psychometric tool for explaining the contribution religion makes to moral decisionmaking. In the present article, we primarily sought to establish and validate a shortened scale that would allow researchers to measure meta-ethical beliefs about divine moral origins in a pragmatic, time-conserving manner. This added pragmatism will facilitate research investigating the role of meta-ethical beliefs in social-moral cognition, religiosity, and related topics, in several ways. First, shorter scales are less taxing on participants, thus reducing concerns for participant fatigue, response quality, and dropout rates. Second, researchers may be more likely to include a shortened scale in their surveys compared to longer forms. This in turn allows room for additional measures in surveys, thus facilitating tests of the unique effects of meta-ethical beliefs. Finally, this added scope for including multiple measures of religiosity in surveys would also 
make it easier to test precisely which aspects of religiosity (e.g., beliefs about the divine origins of morality versus religious attendance, prayer frequency, etc.) best explain the phenomena under investigation.

Beyond this, we also sought to demonstrate novel effects of MFDA endorsement beyond those presented in Piazza and Landy (2013; discussed below) by investigating its role in an increasingly prominent topic in the social sciences: attitudes toward atheists (Studies 1a-1b). Additionally, we sought to investigate the role of beliefs in divine moral authority in determining a person's orientation to: deontological, as opposed to utilitarian, modes of decision-making (Study 2a); and prohibitive morality (Study 2b).

\section{Divine Command Theory (DCT) and its Role in Morality}

Piazza and Landy (2013) developed the MFDA scale to investigate endorsement of Divine Command Theory (DCT), a theory traditionally confined to scholarship in moral philosophy (see e.g., Sinnott-Armstrong, 2009). DCT is the belief that moral rules obtain their truth-value and normative force by virtue of being issued from God or a supreme being. According to one popular version of DCT, God's will is perfect and his knowledge of what is best for humankind is also perfect (on account of God creating humankind); insofar as God wills and knows what is best, God has supreme moral authority in determining what is right and wrong. Furthermore, it is through God's revelation ("scripture") that God's laws for living a moral life are conveyed. Therefore, for devout believers, living a moral life requires knowledge of and adherence to God's moral laws.

DCT is not identical with a deontological approach to morality (indeed, the philosopher Immanuel Kant developed a secular deontological ethical theory based on rational principles). However, among contemporary Christian samples, a belief in divine moral authority appears to 
undergird a deontological approach to morality via commitments to follow divine ordinances, which generally take the form of moral rules (Piazza, 2012; Piazza \& Landy, 2013; Piazza \& Sousa, 2013). Research by Piazza and colleagues has found that people who endorse DCT tend to think that moral rules should be followed even when breaking them would help promote a greater good. They also tend to be fairly pessimistic about humankind's ability to make good moral decisions, which may contribute to their reticence to abandon moral rules in the face of utilitarian alternatives.

Importantly, DCT is also not identical with religiosity—not all religious individuals believe that morality is exclusively founded on divine authority. Some believers have a less pessimistic view about human nature and view moral rules more as helpful guidelines than rigid standards. Accordingly, even among religious believers there is considerable variability in the degree to which individuals hold beliefs about the divine origins of morality (Piazza \& Landy, 2013).

Piazza and Landy (2013) operationalized Divine Command beliefs with a 20-item scale measuring the belief that Morality is Founded on Divine Authority (MFDA). In a series of naturalistic moral dilemmas, MFDA was an important mediator between religiosity and nonutilitarian moral decision-making (e.g., judging it wrong to lie even when lying produces greater welfare for all). MFDA also mediated the relationship between religiosity and endorsement of moral concerns that are typically promoted more in religious than in secular moral systems (e.g., ingroup loyalty, deference to authority/tradition, and concerns for bodily/spiritual purity; Graham \& Haidt, 2010).

Hence, there is some evidence that Divine Command beliefs are important in understanding variability in moral values, judgments, and beliefs, and that the MFDA scale is a 
valid operationalization of such beliefs. The current MFDA scale, however, contains 20 items, which is highly impractical within research attempting to address several constructs (e.g., multiple aspects of religiosity) within a single study. Furthermore, the scale has not been subjected to confirmatory factor analysis. Some of the items may be superfluous if the same level of internal reliability can be attained with fewer items. Accordingly, our primary goal was to develop an equally reliable short-form of the MFDA scale with comparable levels of construct, convergent, and incremental validity as the long-form. Beyond this, we sought to extend previous application of this scale to explore its role in shaping attitudes toward atheists, who by their disbelief challenge the notion that morality is founded on divine authority.

\section{Divine Command Beliefs and Anti-Atheist Prejudice}

Atheists are among the most loathed and distrusted groups in the U.S. (Edgell et al., 2006; Gervais, Shariff, \& Norenzayan, 2011), prompting increasing attention toward anti-atheist prejudice in recent research (see Gervais, 2013). Gervais et al. (2011) found that negative attitudes toward atheists, at least in North America, revolve specifically around moral distrust; however, it is not entirely clear why atheists are distrusted. Some evidence from Gervais et al. suggests it is because atheists are thought to lack the same moral motivations as theists, by virtue of not believing in an afterlife or fearing God's punishment. However, it may also be because atheists are perceived to lack a codified moral system, transmitted through the teachings of a religious community and holy texts, rendering them "moral wildcards" without a firm, moral foundation to their actions (see Gervais, 2013; Sinnott-Armstrong, 2009). This directly implicates Divine Command beliefs in anti-atheist prejudice: If distrust of atheists emerges chiefly from the perception that atheists lack a firm moral system to guide their actions and 
decisions, then the belief that morality comes from God should be a strong factor in shaping attitudes toward nonbelievers.

In the present research, we extend Gervais and colleagues' perspective by testing whether anti-atheist prejudice is predominantly exhibited by individuals who believe that morality originates with God. This would be consistent with the view that it is the perception that atheists lack a moral foundation that really underlies anti-atheist prejudice. Thus, our investigation of anti-atheist prejudice allowed us to test not only the predictive validity of the MFDA instrument but also the hypothesis - posited by Gervais and colleagues - that moral distrust is fundamental to anti-atheist prejudice.

Hypotheses. We made two hypotheses concerning anti-atheist prejudice: First, we hypothesized that belief in divine moral authority (measured via the MFDA scale) is the specific aspect of religiosity most strongly associated with anti-atheist prejudice. Second, we hypothesized that divine moral authority beliefs would correlate more strongly with moral evaluations of atheists compared to other types of evaluations - for example, ratings of atheists' competence or sociability.

As a related yet exploratory concern, in Study 1a we also investigated the role of Divine Command beliefs in attitudes toward science. At least in the U.S., science and religion compete for explanatory space and cultural authority, and are thus are locked in a sometimes-turbulent battle (e.g., Preston \& Epley, 2009). Accordingly, Gauchat (2015) found that religious believers - particularly those who endorse literal interpretation of scripture - are less likely to endorse the cultural authority of science. People who endorse scripture as containing the foundations of morality might distrust science also for fear that naturalism/empiricism will erode the moral tenets upon which their faith is grounded. Thus, we speculated that individuals who 
endorse Divine Command beliefs might be more distrusting of science because they see secular science as a threat to religion's cultural/moral authority.

\section{Item Selection and Scale Validation}

We originally aimed to reduce the 20 -item scale to around $7-8$ items. To determine which items to retain, we sought an approach that was conceptually driven (i.e., observing the various contents and concerns within each item) but also statistically validated.

Conceptual basis for item selection. In Piazza and Landy’s (2013) original work, the full 20-item scale was highly reliable $(\alpha=.98)$ and tapped a unitary construct (a single factor explained $71.20 \%$ of total variance). Despite such evidence for a single factor, we noticed subtle variation across the items regarding their conceptual contents; for example, items appear to encompass at least two related aspects of moral pessimism: (a) pessimism about human knowledge (people lack the necessary knowledge to be moral and thus should follow God's authority); and (b) pessimism about human behavior (people will inevitably err if they attempt to be good on their own). Given the high factor loadings of all 20 items, we decided that an optimal approach to scale reduction was to ensure that the final selection of items adequately covered the diverse conceptual matter of the original scale. (We also sought to retain one or two reverse-scored items, to reduce the impact of acquiescence bias.) We focused on the various ways in which the items addressed beliefs about God's role in shaping human morality. At face value, the items appear to conceptually cover at least three different types of concern:

1. Whether moral knowledge/certainty is accessible only by God (moral knowledge)

2. Whether people can do the right thing without God's help (moral behavior)

3. Whether God determines what is morally right/wrong (divine determinacy) 
There is of course conceptual overlap between these three types of beliefs; for example, the third category is very similar to the first, but ascribes even more power to divine mandate. Indeed, some scale items cover more than one type of concern. Nevertheless, there are subtle conceptual differences between each category of items; hence, neglecting a certain category might lead to a scale with a limited capacity to capture between-person variability in beliefs about divine origins of morality. It was thus important that our final selection of items adequately addressed each subtly different type of Divine Command belief. Our final selection of items based on this criterion is displayed in Table 1 (see Study 1a for the process that led to a final selection of only five of these items).

Scale validation. We sought to establish a shortened version of the MFDA that meets the following criteria. First, the scale should demonstrate construct validity - the items should be internally reliable and should tap a single construct (as with the 20-item scale). Second, the scale should demonstrate convergent validity —it should be strongly associated with various measures of religiosity, such as religious attendance, religious identity, and Biblical literalism; it should also moderately correlate with measures that are conceptually related to and typically associated with religiosity, such as right-wing authoritarianism (RWA) and the moral foundations of Authority, Ingroup Loyalty, and Sanctity (Graham \& Haidt, 2010). Finally, the scale should demonstrate incremental validity — it should predict relevant constructs (e.g., nonutilitarian moral decision-making) independent of other factors that have been shown to be statistically associated with these constructs. 


\section{Table 1}

Items selected for the shortened Morality Founded on Divine Authority scale, and factor loadings of the focal 5 items.

\begin{tabular}{|c|c|c|c|c|}
\hline & ITEM & $\begin{array}{l}\text { Type of } \\
\text { Concern }\end{array}$ & $\begin{array}{c}\text { Factor } \\
\text { loadings }{ }^{\dagger} \\
(\text { Study } 1 a)\end{array}$ & $\begin{array}{c}\text { Factor } \\
\text { loadings^} \\
(\text { Study } 2 a)\end{array}$ \\
\hline 1 & $\begin{array}{l}\text { Everything we need to know about living a moral life } \\
\text { God has revealed to us }\end{array}$ & 1,2 & .904 & .947 \\
\hline 4 & $\begin{array}{l}\text { What is morally good and right is what God says is good } \\
\text { and right }\end{array}$ & 3 & .929 & .948 \\
\hline 7 & $\begin{array}{l}\text { If you want to know how to live a moral life you should } \\
\text { look to God }\end{array}$ & 1,2 & .864 & .930 \\
\hline 9 & $\begin{array}{l}\text { Acts that are immoral are immoral because God forbids } \\
\text { them }\end{array}$ & 3 & .833 & .916 \\
\hline 13 & $\begin{array}{l}\text { Right and wrong can never be explained with human } \\
\text { logic, they can only come from God's commands }\end{array}$ & 1,3 & - & - \\
\hline 14 & $\begin{array}{l}\text { Without God's revelation, people would have no way to } \\
\text { know right from wrong }\end{array}$ & 1 & - & - \\
\hline 17 & $\begin{array}{l}\text { It is possible to live a righteous life without knowledge of } \\
\text { God's laws* }\end{array}$ & 1,2 & .626 & .691 \\
\hline 19 & $\begin{array}{l}\text { Without God, humans still have a way to distinguish } \\
\text { right from wrong* }\end{array}$ & 1 & - & - \\
\hline
\end{tabular}

Note: Types of Concern as follows:

$l=$ whether moral knowledge/certainty is accessible only by God;

$2=$ whether people can do the right thing without God's help;

$3=$ whether God determines what is morally right/wrong.

*Reverse-scored; $\quad \nmid$ Confirmatory Factor Analysis; $\quad \wedge$ Principal Components Analysis without rotation;

- indicates items that were removed in Study 1a to increase model fit.

\section{STUDY 1a:}

\section{Scale Reduction and Confirmatory Analysis with U.S. Religious Believers}

In Study 1a we sought to establish the construct validity of a shortened scale via

Confirmatory Factor Analysis (CFA). Beyond this, we tested the scale's convergent validity by

observing correlations with existing measures of religiosity. We also tested the scale's 
incremental validity by observing associations with anti-atheist prejudice and trait ratings of atheists on the dimensions of morality, sociability, and competence (we expected the MFDA scale to correlate most strongly with morality ratings of atheists). Finally, for exploratory purposes we included measures addressing Biblical literalism and beliefs about the cultural authority of science.

\section{Method}

\section{Participants}

Three-hundred and four U.S. participants completed an online survey hosted by Amazon's Mechanical Turk for $\$ 0.50$ compensation. We recruited only those who initially reported believing in God to avoid attaining skewed results (floor effect) from non-theists. We removed eight participants from analysis for responding incorrectly to any two of three attentioncheck items (e.g., "click 5 so we know you're paying attention"), and a further three participants for claiming to not believe in God. This left a total sample of 293 participants (107 males, 185 females, one preferring not to say), $M_{a g e}=36.3, S D=13.4$. Participants' religious identifications were as follows: 226 Christians (76.7\%), 3 Jews (1.0\%), 2 Hindus (.7\%), 11 Muslims (3.8\%), 4 Buddhists (1.4\%), 21 selecting “other" (7.2\%), and 27 agnostics (9.2\%; self-identifying agnostics, like all other participants, claimed to believe in God).

\section{Materials}

We included only the focal eight MFDA items from the larger 20 item scale; participants responded on a 1 (strongly disagree) to 9 (strongly agree) scale (mean scores presented in Results). We also included a measure of Biblical literalism (Gauchat, 2015): Participants were asked "Which of the following comes closest to describing your feelings about the bible?": $0=$ 
BELIEF IN DIVINE MORAL AUTHORITY

The Bible is an ancient book offables, legends, history, and moral precepts recorded by men; 50 $=$ Unsure/undecided; $100=$ The Bible is the actual word of God and is to be taken literally, word for word $(M=55.23, S D=34.48)$. Our other measures of religiosity included a measure of Religious Attendance ("How often do you attend religious services, apart from social obligations such as weddings or funerals?" $1=$ never, $6=$ every week or more than once a week; $M=3.35$, $S D=1.70)$, a measure of Prayer Frequency $(1=$ never, $7=$ more than once a day; $M=4.82, S D$ = 2.03), and Preston and Epley's (2005) four-item measure of belief in God (e.g., "How confident are you that God exists?"; $1=$ not at all, $11=$ extremely; $\alpha=.97 ; M=8.24, S D=$ 2.90).

To assess anti-atheist prejudice, we used Gervais' (2011) 7-item Negative Attitudes Toward Atheists (NATA) scale (e.g., "I would be uncomfortable with an atheist teaching my child"; $\alpha=.89 ; M=3.85, S D=1.50$ ). We also included a list of 19 traits taken from Landy, Piazza, and Goodwin (in preparation) $)^{1}(1=$ doesn't describe atheists well at all, $9=$ describes atheists very well). We included Gauchat's (2015) two-item measure of beliefs about the cultural authority of science: "Even if it brings no immediate benefits, scientific research that advances the frontiers of knowledge is necessary and should be supported by the federal government" (reverse-scored) and "Science is too concerned with theory and speculation to be of much use in making concrete government policy decisions that will affect the way we live" ( $l=$ strongly disagree, $6=$ strongly agree $)$. These two items $(r=.48, p<.001)$ were averaged to form a measure of Negative Attitudes toward Science (NATS; high scores indicate an opposition to science; $M=2.63, S D=1.20)$.

To address participants' moral values, we included the standard 30-item Moral Foundations Questionnaire (MFQ), comprised of two subscales across the five foundations (see 
Graham et al., 2011). Items pertaining to each foundation were collapsed to form measures of foundation endorsement $(\alpha \mathrm{s}=.65-.86)$.

Participants also completed a 15-item measure of Right-Wing Authoritarianism (RWA; Zakrisson, 2005), measuring respect for and strict deference to tradition and authority (e.g., "God's laws about abortion, pornography and marriage must be strictly followed before it is too late; violations must be punished"; $\alpha=.90 ; M=3.52, S D=1.20$ ). Basic demographics were also assessed, including two items assessing political ideology: "What is your political stance regarding social issues?" and "What is your political stance regarding economic issues?" $(1=$ extreme left, $6=$ centrist, $11=$ extreme right $; M \mathrm{~s}=5.68$ and $6.21, S D \mathrm{~s}=2.90$ and 2.80 , respectively).

\section{Procedure}

To avoid the possible impact of order effects (e.g., presenting MFDA first might increase anti-atheist prejudice) we used a nuanced randomization procedure. First, measures of MFDA, distrust of science, and Biblical literalism were presented in randomized order. Second, we randomized presentation order of measures of anti-atheist prejudice (the NATA scale and the list of 19 traits). Then, these two sets of measures were presented in random order. Following this, participants completed the MFQ, RWA, provided demographic information, and were then debriefed. Within each measure, item order was randomized across participants.

\section{Results}

The eight-item MFDA scale was reliable $(\alpha=.93)$ and normally distributed: $M=4.90$, $S D=2.20$, skewness $=-.017(S E=.142)$.

\section{Construct Validity}


We first subjected the eight MFDA items to a Confirmatory Factor Analysis (CFA) using Maximum Likelihood Estimation (MLE; the most common method of estimation in CFA and appropriate for continuous, normally distributed variables; Brown, 2015). In line with an EFA of the full 20-item scale (Piazza \& Landy, 2013), a one-factor solution consistently provided better fit than a two- or three-factor solution (we tested for two- and three-factor solutions by categorizing items based on the three putative components of Divine Command Theory discussed in the Introduction; see Table 1). Nevertheless, even in a one-factor solution the eight items yielded inadequate fit. We thus sought to improve model fit by removing problematic items one at a time.

All items yielded acceptable factor loadings (all >.50; see Table 1), suggesting that the poor fit was due to inter-item redundancies (i.e., certain items might be unnecessary if their content is adequately covered in another item). We therefore inspected modification indices, which reveal whether certain items share overlapping variance not accounted for by the target factor. Items revealing particularly large overlap with other items were deleted, one at a time, beginning with the most apparently problematic items (see Table 2). We relied on several contrasting criteria in order to optimize model fit, namely: (a) a Chi-square test to ensure adequate fit between the observed and expected covariance matrices (and a Normed Chi-square test to account for the impact of degrees of freedom); (b) the Root Mean Square Error of Approximation (RMSEA) to ensure adequate approximation of the model to population characteristics; (c) a Comparative Fit Index (CFI) to indicate model improvement over a baseline model that assumes zero population covariances among the observed variables; and (d) the Standardized Root Mean Square Residual (SRMR) to index the mean absolute correlation residual (i.e., the overall difference between the observed and predicted correlations). 
A five-item solution was the only outcome that satisfied all criteria for "good" model fitness (see Table 2 table notes). This was the only solution that satisfied all four goodness-of-fit criteria. Importantly, this five-item solution retains one reverse-scored item, thus reducing concerns regarding acquiescence bias. Moreover, the scale adequately covers the various conceptual concerns that we used as an initial guide to scale reduction (see Table 1). It also showed strong inter-item reliability $(\alpha=.92)$. We therefore settled on this five-item scale and sought to validate it in further analyses. Like the 8-item scale, this 5-item scale was normally distributed $-M=5.32, S D=2.34$, skewness $=-.237(S E=.142)$. As the mean approximated the scale midpoint, participants on average gave neutral responses to statements about the divine origins of morality.

\section{Table 2}

Confirmatory factor analysis to determine a final scale with good model fit (Study 1a).

\begin{tabular}{|c|c|c|c|c|}
\hline $\begin{array}{c}\text { Fitness } \\
\text { Criterion }\end{array}$ & 8 items & $\begin{array}{c}\mathbf{7} \text { items } \\
\text { (item } 19 \text { removed) }\end{array}$ & $\begin{array}{c}\mathbf{6} \text { items } \\
\text { (items } 19 \& 14 \\
\text { removed) }\end{array}$ & $\begin{array}{c}\mathbf{5} \text { items } \\
\text { (items } 19,14, \& 13 \\
\text { removed) }\end{array}$ \\
\hline$\chi^{2}$ test of model & $150.85(20)$ & $92.63(14)$ & $46.71(9)$ & $7.68(5)$ \\
\hline fit $(d f)$ & $p<.001$ & $p<.001$ & $p<.001$ & $p=.178$ \\
\hline $\begin{array}{c}\text { Normed } \chi^{2} \\
\left(\chi^{2} / \mathrm{df}\right)\end{array}$ & 7.54 & 6.62 & 5.19 & 1.54 \\
\hline RMSEA & .149 & .138 & .120 & .043 \\
\hline $90 \% \mathrm{CI}$ & $.128, .172$ & $.112, .166$ & $.087, .155$ & $.000, .099$ \\
\hline $\begin{array}{r}p(\text { RMSEA } \\
\leq .05)\end{array}$ & $<.001$ & $<.001$ & $<.001$ & .509 \\
\hline CFI & .910 & .946 & .972 & .998 \\
\hline SRMR & .064 & .043 & .032 & .015 \\
\hline
\end{tabular}

"Good" fit indicated by:

$\chi^{2}: p>.05$; Normed $\chi^{2}<2.0$; RMSEA $<.05$; CFI $>.950$; and SRMR $<.06$. 


\section{Convergent validity}

All zero-order correlations are displayed in Table 3. As expected, MFDA was strongly associated with measures of religiosity (Biblical Literalism, Prayer Frequency, Religious Attendance, and Belief in God) and RWA (which shares in common with MFDA concerns for hierarchical deference and traditional religious order), and was moderately-to-strongly correlated with the two moral foundations that moralize deference to superiors and purity/sanctity. Additionally, MFDA was very strongly associated with NATA, suggesting that Divine Command beliefs and anti-atheist prejudice, although distinct constructs, share a large degree of overlap (this is also despite the fact that, unlike in the original scale, no MFDA item explicitly mentioned atheists).

We then assessed the varying role of MFDA in predicting different types of beliefs about atheists. We categorized traits based on conceptual criteria and formed composites addressing perceived atheist Morality, Moral-competence, Sociability, and Competence (see Footnote 1 for details; all $\alpha \mathrm{s}>.88) .^{2}$ Means (and SDs) were 5.25 (1.87), 5.18 (1.77), 5.55 (1.61), and 5.59 (1.74), respectively (1-9 scale; high scores indicate positive appraisals). Consistent with the notion that moral distrust underlies anti-atheist prejudice (Gervais, 2013), the strongest correlations emerged between MFDA and moral trait ratings of atheists: $r$ s $=-.47,-.43,-.30$, and -.35 , respectively, all $p \mathrm{~s}<.001$; that is, Divine Command beliefs were most associated with negative views about atheists' moral character, as opposed to other aspects of their personality or intelligence. To provide an even stronger test of the hypothesis, we used the approach outlined by Lee and Preacher (2013) to compare relative strengths of correlations. The correlation with Morality was stronger than all other correlations, all zs >2.36, $p$ s (2-tailed) <.018. In addition, MFDA correlated with Moral-competence more strongly than with either Sociability or 
Competence, $z \mathrm{~s}>2.53, p \mathrm{~s}<.012$ (and with Competence more strongly than with Sociability, $z$ $=1.99, p=.047)$. Hence, MFDA was most strongly associated with the perception that atheists lack moral character, including competence traits with a distinctly moral flavor.

\section{Incremental Validity ${ }^{3}$}

We reasoned that MFDA should be the strongest unique predictor of attitudes toward atheists because atheism represents the antithesis of divine command beliefs. Multiple regressions are displayed in Table 4. As expected, MFDA explained more variability in NATA compared to all other measures.

We also explored the role of MFDA in explaining beliefs about the cultural authority of science, as past research has found that religious believers are less likely to endorse science's cultural authority (e.g., Gauchat, 2015). Consistent with expectations, MFDA was consistently a unique (and positive) predictor of negative attitudes toward science. Only measures pertaining to political ideology explained more variance than MFDA, and even here, when ideology covariates were addressed separately alongside MFDA, MFDA was always the stronger predictor, even compared to RWA $\left(\beta_{\mathrm{MFDA}}=.56, \beta_{\mathrm{RWA}}=.37, p \mathrm{~s}<.001\right)$. Hence, belief in divine moral authority is a central factor in explaining religious believers' attitudes toward science. 


\section{Table 3}

Zero-order correlations (Study 1a).

\begin{tabular}{|c|c|c|c|c|c|c|c|c|c|c|c|c|c|c|}
\hline & 2. & 3. & 4. & 5. & 6. & 7. & 8. & 9. & 10. & 11. & 12. & 13. & 14. & 15. \\
\hline 1. MFDA & $.84^{\circ}$ & $.46^{\circ}$ & $.83^{\circ}$ & $.51^{\circ}$ & $.55^{\circ}$ & $.73^{\circ}$ & $.55^{\circ}$ & $.38^{\circ}$ & $.72^{\circ}$ & - & $-.17^{\dagger}$ & $.40^{\circ}$ & $.48^{\circ}$ & $.73^{\circ}$ \\
\hline 2. NATA & & $.48^{\circ}$ & $.76^{\circ}$ & $.48^{\circ}$ & $.52^{\circ}$ & $.69^{\circ}$ & $.58^{\circ}$ & $.41^{\circ}$ & $.78^{\circ}$ & - & $-.15^{\dagger}$ & $.40^{\circ}$ & $.49^{\circ}$ & $.72^{\circ}$ \\
\hline 3. NATS & & & $.45^{\circ}$ & $.24^{\circ}$ & $.22^{\circ}$ & $.30^{\circ}$ & $.52^{\circ}$ & $.45^{\circ}$ & $.54^{\circ}$ & $-.20^{\dagger}$ & $-.30^{\circ}$ & $.29^{\circ}$ & $.33^{\circ}$ & $.43^{\circ}$ \\
\hline $\begin{array}{l}\text { 4. Biblical } \\
\text { Literalism }\end{array}$ & & & & $.50^{\circ}$ & $.48^{\circ}$ & $.63^{\circ}$ & $.52^{\circ}$ & $.33^{\circ}$ & $.65^{\circ}$ & - & $-.17^{\dagger}$ & $.41^{\circ}$ & $.43^{\circ}$ & $.66^{\circ}$ \\
\hline $\begin{array}{l}\text { 5. Religious } \\
\text { Attendance }\end{array}$ & & & & & $.49^{\circ}$ & $.48^{\circ}$ & $.30^{\circ}$ & $.22^{\circ}$ & $.36^{\circ}$ & - & - & $.25^{\circ}$ & $.23^{\circ}$ & $.41^{\circ}$ \\
\hline $\begin{array}{l}\text { 6. Prayer } \\
\text { Frequency }\end{array}$ & & & & & & $.73^{\circ}$ & $.28^{\circ}$ & $.13^{*}$ & $.36^{\circ}$ & - & - & $.12 *$ & $.17^{\dagger}$ & $.37^{\circ}$ \\
\hline $\begin{array}{l}\text { 7. Belief in } \\
\text { God }\end{array}$ & & & & & & & $.38^{\circ}$ & $.23^{\circ}$ & $.50^{\circ}$ & $.10^{\wedge}$ & - & $.26^{\circ}$ & $.31^{\circ}$ & $.52^{\circ}$ \\
\hline $\begin{array}{l}\text { 8. Social } \\
\text { Conservatism }\end{array}$ & & & & & & & & $.75^{\circ}$ & $.63^{\circ}$ & $-.18^{\dagger}$ & $-.31^{\circ}$ & $.38^{\circ}$ & $.48^{\circ}$ & $.53^{\circ}$ \\
\hline $\begin{array}{l}\text { 9. Economic } \\
\text { Conservatism }\end{array}$ & & & & & & & & & $.45^{\circ}$ & $-.25^{\circ}$ & $-.33^{\circ}$ & $.36^{\circ}$ & .39 & .34 \\
\hline 10. RWA & & & & & & & & & & - & $-.28^{\circ}$ & $.51^{\circ}$ & $.62^{\circ}$ & $.75^{\circ}$ \\
\hline Moral Foundo & ons: & & & & & & & & & & & & & \\
\hline 11. Care & & & & & & & & & & & $.62^{\circ}$ & $.13 *$ & - & - \\
\hline 12. Fairness & & & & & & & & & & & & - & - & - \\
\hline 13. Loyalty & & & & & & & & & & & & & $.62^{\circ}$ & $.46^{\circ}$ \\
\hline 14. Authority & & & & & & & & & & & & & & $.61^{\circ}$ \\
\hline 15. Sanctity & & & & & & & & & & & & & & \\
\hline
\end{tabular}

To reduce cluttering, we exclude $r s<.10$ (all pertinent $p s>.10$ ).

$M F D A=5$-item Morality Founded on Divine Authority scale; NATA=Negative Attitudes Toward Atheists; NATS= Negative Attitudes Toward Science; $R W A=$ Right-Wing Authoritarianism;

$\wedge p<.10 ; \quad * p<.05 ; \quad{ }^{\dagger} p<.01 ; \quad{ }^{\circ} p<.001$ 


\section{Table 4}

Step-wise regressions testing the incremental validity of the shortened MFDA Scale (Study Ia).

\begin{tabular}{|c|c|c|c|c|c|}
\hline \multirow{3}{*}{$\begin{array}{c}\text { Covariate } \\
\text { Set }\end{array}$} & \multirow{3}{*}{$\begin{array}{l}\text { Predictor } \\
\text { Variable }\end{array}$} & \multicolumn{4}{|c|}{ Dependent Measure } \\
\hline & & \multicolumn{2}{|c|}{ NATA } & \multicolumn{2}{|c|}{$\underline{\text { NATS }}$} \\
\hline & & $\boldsymbol{\beta}$ & $R^{2}$ change & $\boldsymbol{\beta}$ & $R^{2}$ change \\
\hline- & $M F D A$ & $.83 * * *$ & .69 & $.48 * * *$ & $.23 * * *$ \\
\hline \multirow{5}{*}{ Religiosity } & $M F D A$ & $.53 * * *$ & - & $.36 * * *$ & - \\
\hline & $\begin{array}{l}\text { Religious } \\
\text { Attendance }\end{array}$ & .02 & \multirow{4}{*}{$.04 * * *$} & -.02 & \multirow{4}{*}{$.02 n s$} \\
\hline & $\begin{array}{l}\text { Prayer } \\
\text { Frequency }\end{array}$ & .01 & & -.02 & \\
\hline & Belief in God & $.18^{* *}$ & & -.06 & \\
\hline & $\begin{array}{l}\text { Biblical } \\
\text { Literalism }\end{array}$ & $.20 * * *$ & & $.21 *$ & \\
\hline \multirow{4}{*}{$\begin{array}{l}\text { Political } \\
\text { Ideology }\end{array}$} & $M F D A$ & $.55 * * *$ & - & $.14^{*}$ & - \\
\hline & $\begin{array}{l}\text { Social } \\
\text { Conservatism }\end{array}$ & .05 & & $.16^{\wedge}$ & \multirow{3}{*}{$.13 * * *$} \\
\hline & $\begin{array}{l}\text { Economic } \\
\text { Conservatism }\end{array}$ & .02 & $.07 * * *$ & $.17 *$ & \\
\hline & RWA & $.34 * * *$ & & $.26 * *$ & \\
\hline \multirow{6}{*}{$\begin{array}{c}\text { Moral } \\
\text { Foundations }\end{array}$} & $M F D A$ & $.64 * * *$ & - & $.25 * *$ & - \\
\hline & Care & .03 & & -.10 & \multirow{5}{*}{$.08 * * *$} \\
\hline & Fairness & -.04 & & $-.18 * *$ & \\
\hline & Loyalty & -.02 & $.04 * * *$ & .07 & \\
\hline & Authority & .06 & & .07 & \\
\hline & Sanctity & $.23 * * *$ & & $.18^{*}$ & \\
\hline
\end{tabular}

MFDA=5-item Morality Founded on Divine Authority scale; NATA=Negative Attitudes Toward Atheists; NATS=Negative Attitudes Toward Science;

${ }^{\wedge} p<.07 ; \quad * p<.05 ; \quad * * p<.01 ; \quad * * * p<.001$.

\section{Discussion}

In Study 1a we established and validated a shortened, 5-item measure of Divine Command beliefs. This measure met all our criteria for scale validity. Moreover, we found novel support for the notion that moral distrust drives anti-atheist prejudice (Gervais, 2013; Gervais et al., 2011). MFDA beliefs consistently formed the strongest predictor of negative attitudes toward atheists, even when entered into models alongside several other measures of 
religiosity, measures of ideology, or measures of moral values. Although MFDA did not fully mediate the effects of all covariates, it drastically reduced their effect sizes. For example, strong correlations between the four religiosity covariates and NATA $(r \mathrm{~s}=.48-.76)$ were reduced to $\beta \mathrm{s}$ $=.01-.20$. MFDA was consistently the strongest predictor, suggesting that beliefs about the divine origins of morality are central to anti-atheist prejudice.

We also found novel evidence that Divine Command beliefs predict negative attitudes toward science. Although we replicated Gauchat's (2015) key finding that Biblical literalism significantly and uniquely predicted negative attitudes toward science, we found MFDA to be an even stronger predictor. This suggests that although generally held beliefs in the literal truth of the Bible are important in religious believers' attitudes toward science, it is the Biblical literalists' concerns about how science may challenge the religious foundations of morality that are really cause for their distrust.

\section{STUDY 1b: Replication with an Indian Hindu Sample}

In Study 1b we sought further support for the shortened MFDA scale's incremental validity. We ran a study similar to Study 1a in that the focus was on attitudes toward atheists. However, we ran the study with a sample of Indian Hindus, who believe in a supreme God that takes on various forms (pantheism). Study $1 \mathrm{~b}$ represents the first attempt at validating the MFDA outside of a Western, Judeo-Christian context — an important step in testing the cultural bounds of divine command beliefs.

\section{Method}

\section{Participants}


Eighty-three participants in India took part online via Mechanical Turk and received \$0.40 compensation. We removed six participants who answered any two of three attentioncheck items incorrectly, leaving a final sample of 77 participants (51 males), $M_{\text {age }}=32.5, S D=$ 9.0. Only two participants did not identify as Hindu (one 'atheist', one 'other'), and a further five claimed to not believe in "a God or Gods". Removing these participants did not affect the direction or significance of any effect (moreover, as Hindus tend to place relatively greater emphasis on religious practice rather than deistic belief compared to U.S. Christians-e.g., Hughes et al. [2015] — we were reluctant to remove these participants based on their lack of deistic belief.)

\section{Materials and Procedure}

Participants first completed the 7-item NATA scale $(\alpha=.74 ; M=4.02, S D=.94)$. They then completed the full, 20-item version of the MFDA (this study was conducted prior to Study 1a, hence the inclusion of the full, original scale). The focal five items derived from the CFA in Study 1a were reliable $(\alpha=.81)$, and participants tended to respond near the scale midpoint $(M=$ $5.45, S D=1.44)$.

Participants then completed the same 15-item measure of RWA as in Study 1a ( $\alpha=.78$; $M=4.87, S D=.67)$. They then provided demographic information. Measures addressing Religious Attendance $(M=4.29, S D=1.30)$, Prayer Frequency $(M=5.33, S D=1.67)$, Preston and Epley's (2005) four-item measure of belief in God $(\alpha=.96 ; M=8.26, S D=2.43)$, and social/economic conservatism $(M \mathrm{~s}=6.93$ and $6.95, S D \mathrm{~s}=2.32$ and 2.47 , respectively) were the same as in Study 1a. (The survey also included the 30-item MFQ, but we excluded MFQ scores from analyses because the scales were unreliable in this sample of Indian Hindus.)

\section{Results and Discussion}


MFDA's zero-order associations (Table 5) were very similar to those in Study 1a (Table 3). NATA was significantly associated with all religiosity covariates; unexpectedly, however, it was not significantly associated with any ideology covariate. Nevertheless, we explored whether MFDA would predict NATA independently of these covariates (see Table 6). Overall, the effects of MFDA were robust to the inclusion of all covariates, and MFDA was consistently the strongest predictor of NATA. Moreover, despite strong zero-order associations between the religiosity covariates and NATA, MFDA explained the majority of variance in NATA and reduced the effects of all religiosity covariates apart from Belief in God to non-significance. Furthermore, in models including MFDA and only a single covariate, MFDA was consistently significant and the strongest unique predictor.

These results replicate findings from Study 1a in showing that the belief that morality comes directly from God is the strongest predictor of attitudes toward atheists. The similar patterns of results across Studies 1a/1b suggest that results are not artifacts of sample size and are not particular to U.S. Christians, as highly similar associations emerged in the sample of Indian Hindus. 


\section{Table 5}

Zero-order correlations (Study 1b).

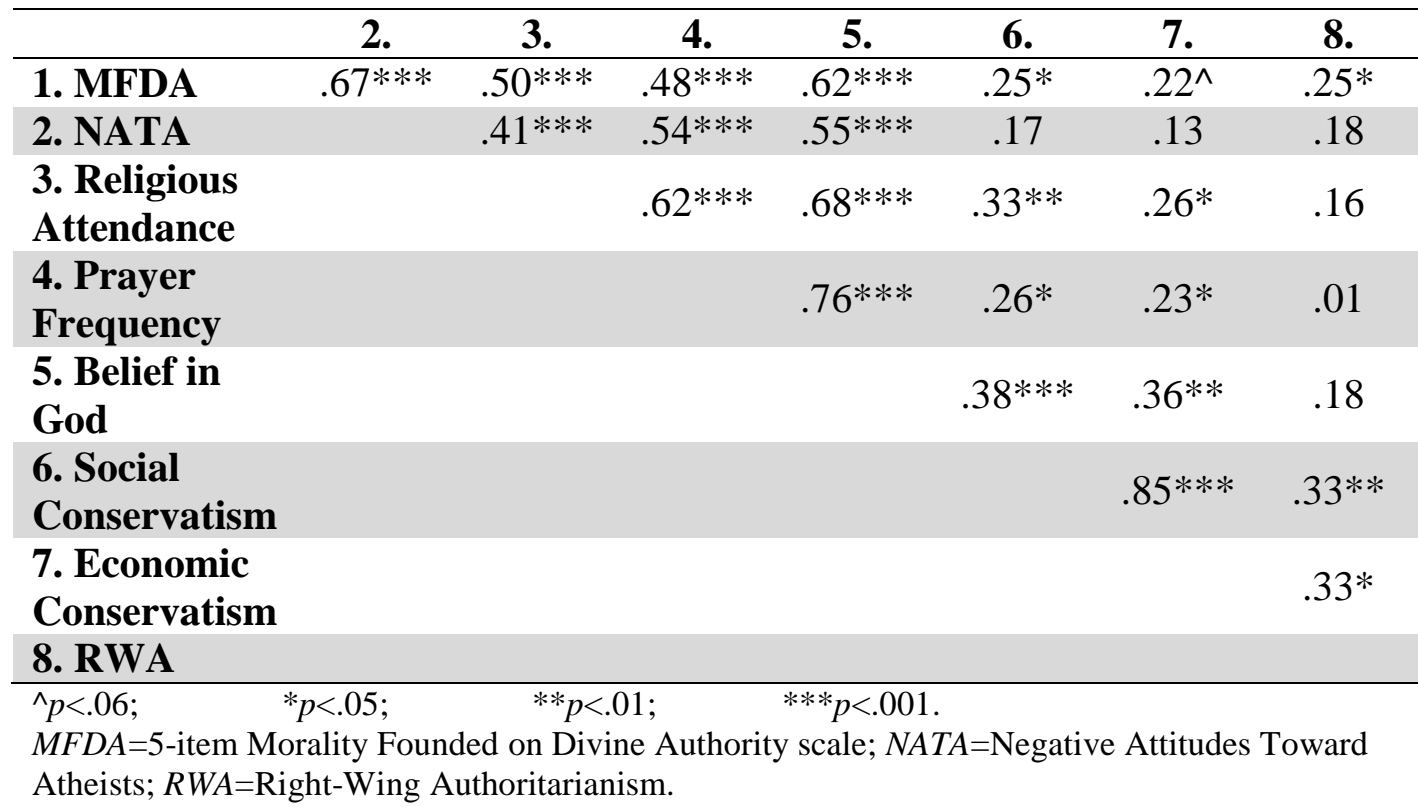

\section{Table 6}

Step-wise regressions: MFDA, ideology, and religiosity predicting negative attitudes toward atheists (Study $1 b$ ).

\begin{tabular}{cccc}
\hline Covariate Set & $\begin{array}{c}\text { Predictor } \\
\text { Variable }\end{array}$ & $\boldsymbol{\beta}$ & $\boldsymbol{R}^{2}$ change \\
\hline- & $M F D A$ & $.66^{* * *}$ & \\
\hline \multirow{5}{*}{ Religiosity } & $M F D A$ & $.51^{* * *}$ & - \\
& $\begin{array}{c}\text { Religious } \\
\text { Attendance } \\
\text { Prayer } \\
\text { Frequency }\end{array}$ & -.05 & $.28^{*}$ \\
& $\begin{array}{c}\text { Belief in God } \\
\text { Political Ideology }\end{array}$ & .05 & $.06^{*}$ \\
& $\begin{array}{c}M F D A \\
\text { Social } \\
\text { Conservatism }\end{array}$ & $.05 * *$ & - \\
& $\begin{array}{c}\text { Economic } \\
\text { Conservatism }\end{array}$ & -.09 & .002 \\
& RWA & .03 & \\
\hline
\end{tabular}

$M F D A=5$-item Morality Founded on Divine Authority scale; $* p<.05 ; * * * p<.001$. 


\section{STUDY 2: Divine Command Theory and Moral Cognition}

Our goals in Studies 2a-2b were to (a) further demonstrate convergent and incremental validity of the 5-item MFDA scale using an alternative set of measures and (b) demonstrate the utility of this scale in explaining variability in morally relevant constructs independent of other measures of religiosity. In Study 2a, we reanalyzed a preexisting data set from Piazza and Landy (2013, Study 1) now using only the five MFDA items derived from Study 1a. The aim was to show that the MFDA short-form correlated sensibly with other measures of religiosity, yet predicted moral attitudes - in particular, non-utilitarian decision-making - independent of other religiosity measures. Study $2 \mathrm{~b}$ was a new study in which we tested whether MFDA would uniquely predict a prohibitive orientation toward morality.

\section{Study 2a}

\section{Method}

Participants and materials. Piazza and Landy's (2013; Study 1) dataset included 290 U.S. adults (136 male, $M_{\text {age }}=34.0$ years, $\left.S D=11.4\right)$ recruited online. The measures included (a) several measures of religiosity: the original 20-item MFDA scale, the Short Christian Orthodoxy

scale, Santa Clara Strength of Religious Faith Questionnaire, Attitude toward Religion scale, and self-reported religiosity (single item); (b) the 12-item Revised Scale of Social Conservatism for use with U.S. samples (scores ranged from 0-1); (c) Actively Open-minded Thinking scale; (d) a 44-item Big Five Inventory (the 20-item MFDA only weakly correlated with Big Five personality traits, so this measure will not be discussed further); and (e) Piazza and Sousa's (2013) Consequentialist Thinking Style scale. (For further details, see Piazza and Landy, 2013, Study 1.) 
Consequentialist Thinking Style represented our main dependent measure. Participants responded to 14 questions in which they indicated whether a rule violation (e.g., lying, torture, breaking promises) was "never morally permissible" (deontological response), "permissible if it produces more good than bad" (weak utilitarian response), or "obligatory if it produces more good than bad" (strong utilitarian response). Following Piazza and Landy (2013), responses to the 14 items were averaged with scores ranging from 1-3 (higher scores representing a stronger commitment to utilitarian thinking).

\section{Results}

Internal reliability. We conducted a principal components factor analysis on the five MFDA items, without rotation. This produced a single-factor solution (eigenvalue $=3.98$, explaining $79.54 \%$ of the total variance; the second eigenvalue was .59), $\alpha=.94$.

Convergent validity. The MFDA short-form correlated strongly with the Short Christian Orthodoxy Scale, $r(289)=.87$, the Santa Clara Strength of Religious Faith Questionnaire, $r(289)$ $=.87$, the Attitudes towards Religion scale, $r(289)=.77$, and Social Conservatism, $\rho(289)=.70$. These correlations are very similar to those reported by Piazza and Landy (2013, Study 1) using the 20-item MFDA.

Incremental validity. The MFDA short-form correlated negatively with the Actively Open-minded Thinking scale, $r(289)=-.70$ (i.e., endorsement of God as moral authority correlated with being less actively open-minded), and with Consequentialist Thinking Style, $r(289)=-.49$ (i.e., endorsement of God as moral authority negatively correlated with utilitarian thinking), both $p s<.001$. To test the incremental validity of the MFDA short-form, we conducted a regression analysis entering the MFDA short-form into a model simultaneously with other measures of religiosity (Christian Orthodoxy, Strength of Religious Faith, Attitudes toward 
Religion, and self-reported religiosity) predicting Consequentialist Thinking Style scores $\left(R^{2}=\right.$ .248). MFDA emerged as the only significant independent predictor of CTS, $\beta=-.37, t(284)=-$ $3.17, p=.002$, all other $\beta \mathrm{s}<.15, t \mathrm{~s}<1.09, p \mathrm{~s}>.27$. When Actively Open-minded Thinking was added to the model $\left(R^{2}=.258, R_{\text {change }}^{2}=.01\right)$, the MFDA short-form remained a significant independent predictor of consequentialist thinking style, $\beta=-.28, t(283)=-2.25, p=.025$, and Actively Open-minded Thinking was a marginal, independent predictor, $\beta=.14, t(283)=1.92, p$ $=.056$.

\section{Discussion}

The 5-item MFDA behaved very much like the 20-item MFDA as in Piazza and Landy (2013); it converged with other measures of religiosity and discriminantly predicted an important outcome related to moral cognition: deontological thinking. Replicating the findings of Piazza and Landy, the 5-item MFDA even predicted a non-utilitarian thinking style independent of Actively Open-minded Thinking. Overall, Study 2a extends the findings of Study 1 to demonstrate further evidence of the MFDA short-form's convergent validity given strong correlations with measures of religiosity not included in Study 1, and its incremental validity when predicting a widely studied aspect of moral cognition. Study $2 b$ sought to test the incremental validity of the MFDA short-form with regard to yet another facet of moral cognition.

\section{Study 2b}

Prohibitive moral rules specify what is obligatory not to do (e.g., "Do not kill"; "Do not lie"), while prescriptive moral rules specify what is obligatory to do (e.g., "Strive to save lives"; "Strive to tell the truth"). Past research by Janoff-Bulman and colleagues has shown that individuals vary in terms of their relative orientation toward prohibitive and prescriptive moral rules (e.g., Janoff-Bulman, Sheikh, \& Hepp, 2009). Individuals with an avoidant or inhibitive 
self-regulatory style tend to exhibit a predominantly prohibitive moral orientation, whereas individuals with a more approach-oriented or active self-regulatory style tend to exhibit a prescriptive moral orientation (Janoff-Bulman et al., 2009). As far as we are aware, no research to date has examined whether religious belief or participating in a religious community might encourage a prohibitive or prescriptive moral orientation. However, we surmise that a belief in divine moral authority might encourage a prohibitive moral orientation insofar as many divine commands or religious-based moral codes (e.g., the Ten Commandments) tend to be framed as prohibitions (e.g., "Thou shalt not kill”; "Thou shalt not commit adultery"; "Thou shalt not steal”; see Deuteronomy 5:4-21; Exodus 20:1-17, KJV), while much fewer divine commands are framed as prescriptions (one exception being, "Honor thy father and mother"), at least within Judeo-Christian traditions.

In keeping with this theorizing, in Study $2 b$ we tested whether MFDA might uniquely predict a prohibitive moral orientation independent of other aspects of religiosity. We were less sure about the relationship between MFDA and a prescriptive orientation, yet we included a measure of this variable for exploratory purposes.

\section{Method}

Participants. We recruited a new sample of 261 participants via Mechanical Turk (116 female; $M_{\mathrm{age}}=36.2$ years, $\mathrm{SD}=11.3$; we aimed to recruit a minimum of 250). Recruitment was limited to individuals located in the U.S.; 47\% reported a Christian affiliation (Evangelical, Protestant, Catholic, or Other), 3\% Jewish, 5\% Personality Spirituality, 3\% Other religion, 5\% None/no religion, 17\% Agnostic, and 20\% Atheist. Participants received \$0.50 compensation.

Prohibitive and prescriptive morality. Participants rated the extent to which they agreed or disagreed with 30 statements "about what a person is 'morally required' to do," using a 
7-point scale $(1=$ Strongly disagree $;=$ Strongly agree $)$. Half of the statements were framed as prohibitive rules; the other half were framed as prescriptive rules (see Appendix A, for all 30 items and descriptive statistics). The rules were designed to cover a wide range of moral themes and content, with corresponding prohibitive and prescriptive rules for each theme (e.g., not stealing vs. giving to charity, respectively). Both sets of rules exhibited high reliability (Cronbach's $\alpha=.92, .95$, respectively).

MFDA and other religiosity measures. The MFDA short-form was answered in terms of level of agreement, this time on a 1 (Strongly disagree) to 7 (Strongly agree) scale. The internal reliability was high $(\alpha=.91)$. The mean $(3.18, S D=2.02)$ was lower than in Studies 1a$1 \mathrm{~b}$ likely due to the recruitment of non-theists, in addition to theists, driving down the scores. To assess the convergent and incremental validity of the MFDA beyond what has already been demonstrated in Studies 1-2a, we included the Duke University Religion Index (DUREL; Koenig \& Büssing, 2010), a widely used 5-item index of religiosity. The DUREL has been used in over 100 studies and has been shown to be a reliable and valid measure of three major dimensions of religiosity. The first item assesses a person's involvement in Organizational Religious Activity: "How often do you attend church or other religious meetings?" (1= Never, $6=$ More than once $a$ week; $M=2.30, \mathrm{SD}=1.56$ ). The second item measures involvement in Non-Organizational Religious Activities: "How often do you spend time in private religious activities, such as prayer, meditation, or Bible study?" $(1=$ Rarely/never, $6=$ More than once a day; $M=2.38, \mathrm{SD}=1.79)$. The final three items, averaged together, assesses religious identification or Intrinsic Religiosity: "In my life, I experience the presence of the Divine (i.e., God)"; "My religious beliefs are what really lie behind my whole approach to life"; "I try hard to carry my religion over into all other dealings in life" $(1=$ Definitely not true of me, $5=$ Definitely true of me; $\alpha=.93 ; M=2.55, \mathrm{SD}=$ 
1.47). The three DUREL subscales were substantially correlated (see Table 7), and correlated with MFDA (see Table 7); as a conservative test of the MFDA scale's incremental validity, we treated the subscales as separate dimensions in our main analysis.

Procedure. Participants rated the 30 moral rules and then completed the MFDA shortform and DUREL along with other demographic questions. Afterwards, they were debriefed and paid.

\section{Results and Discussion}

Endorsement of the MFDA had a moderate zero-order correlation with both prohibitive and prescriptive moral orientations (see Table 7). The DUREL subscales were also correlated with prohibitive and prescriptive orientations, particularly Intrinsic Religiosity, which had the largest correlations. Additionally, the prescriptive and prohibitive scales were themselves highly correlated, reflecting a general orientation toward moral rules among many participants.

\section{Table 7}

Zero-order correlations (Study 2b).

\begin{tabular}{llllll}
\hline \multicolumn{1}{c}{ Variable } & $\mathbf{2 .}$ & $\mathbf{3 .}$ & $\mathbf{4 .}$ & $\mathbf{5 .}$ & $\mathbf{6 .}$ \\
\hline $\begin{array}{l}\text { 1. MFDA } \\
\text { 2. Organizational } \\
\text { Religious Activities }\end{array}$ & .65 & .72 & .85 & .43 & .37 \\
$\begin{array}{l}\text { 3. Non-organizational } \\
\text { Religious Activities }\end{array}$ & - & .65 & .70 & .21 & .22 \\
$\begin{array}{l}\text { 4. Intrinsic religiosity } \\
\text { 5. Prohibitive moral } \\
\text { orientation }\end{array}$ & - & - & .79 & .31 & .28 \\
$\begin{array}{l}\text { 6. Prescriptive moral } \\
\text { orientation }\end{array}$ & - & - & - & .40 & .38 \\
\hline
\end{tabular}

Note. All correlations: $p<.001 . N=261$. MFDA=5-item Morality Founded on Divine Authority scale; Religiosity measures from Duke University Religion Index. 
To test for incremental validity, we conducted two separate step-wise regressions, the first with prohibitive morality as the outcome variable, and the second with prescriptive morality. For both analyses, we first regressed the MFDA short-form and the demographic variables (gender, political orientation, and level of education) onto the outcome variable. Gender, political orientation, and education were included in Step 1, as they have been shown to be relevant for moral outcomes in past studies (e.g., Piazza, 2012). Second, we added the religiosity measures (DUREL) to the analysis. As expected, MFDA predicted a prohibitive orientation to morality independent of gender, political orientation, education, and various aspects of religiosity (see Table 8). Being female was also an independent predictor of prohibitive morality. Additionally, MFDA predicted a prescriptive orientation independent of these variables, but only to a marginal extent (see Table 9). Gender and intrinsic religiosity were stronger predictors of prescriptive morality than of prohibitive morality.

In short, a belief that morality is founded on divine authority uniquely predicted having a prohibitive orientation toward morality, independent of other aspects of religiosity and relevant demographic factors, but was at best only a marginally significant unique predictor of having a prescriptive orientation toward morality. This further highlights the predictive value and incremental validity of the MFDA short-form as a factor contributing to moral cognition. 


\section{Table 8}

Step-wise Regression: MFDA, demographic, and religiosity variables predicting a prohibitive moral orientation (Study $2 b$ ).

\begin{tabular}{llccc}
\hline \multicolumn{1}{c}{ Variables } & $\boldsymbol{\beta}$ & $\boldsymbol{t}$ & $\boldsymbol{R}^{\mathbf{2}}$ \\
\hline Step 1 - & & & .210 \\
Demographics & & & \\
& MFDA & .38 & $6.03^{* * *}$ & \\
& Female & .17 & $2.90^{* *}$ & \\
& Political conservatism & .02 & $<1$ & \\
Step 2 - & Education & -.02 & $<1$ & .221 \\
Religiosity & & & & \\
& MFDA & .36 & $3.26^{* *}$ & \\
& Female & .15 & $2.51^{*}$ & \\
& Political conservatism & .02 & $<1$ & \\
& Education & -.01 & $<1$ & \\
& Organizational religious & -.13 & -1.51 & \\
$\quad$ activity & & & \\
& Non-organizational & -.05 & $<1$ & \\
& religious activity & & & \\
& Intrinsic religiosity & .16 & 1.28 & \\
\hline
\end{tabular}

$* p<.05 ; * * p<.01 ; * * * p<.001$. MFDA=5-item Morality Founded on Divine Authority scale; Religiosity measures from Duke University Religion Index. 


\section{Table 9}

Step-wise Regression: MFDA, demographic, and religiosity variables predicting a prescriptive moral orientation (Study $2 b$ ).

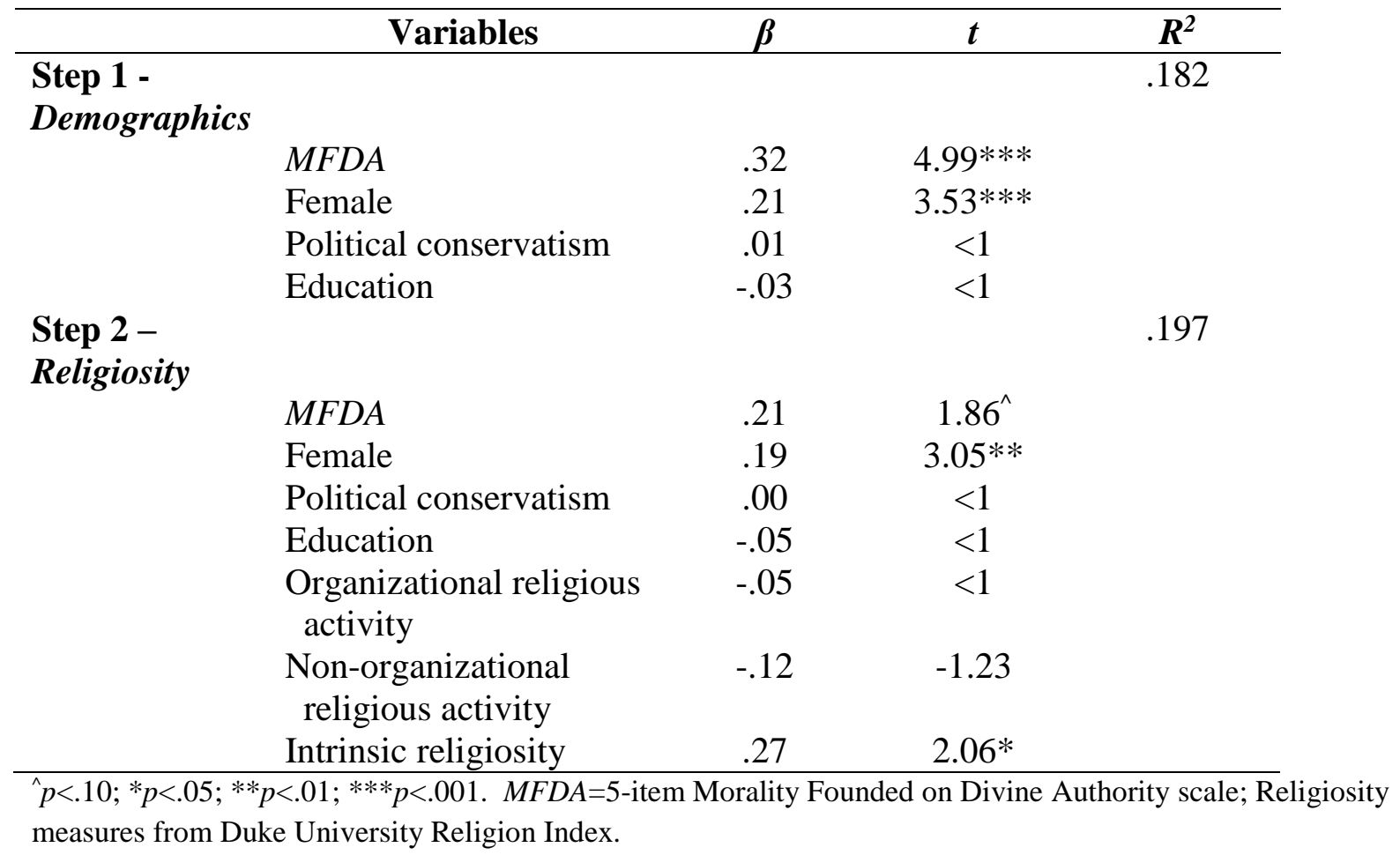

\section{GENERAL DISCUSSION}

In this paper we have established and validated a shortened version of a scale measuring beliefs about the divine origins of morality, reducing a large, 20-item scale to a much more practical 5-item scale.

We began by addressing the diverse conceptual content of the original 20-item scale, ensuring that the reduced scale adequately captures a range of Divine Command beliefs. Accordingly, the final 5-item scale includes items addressing beliefs about whether (a) God has exclusive access to moral knowledge/certainty, (b) people can behave morally without God's help, and (c) God actually determines what is morally right/wrong (see Table 1). Although each 
consideration is conceptually associated, and although statistically they tap a single dimension, subtle differences in their content cautioned us to cover all three in the finalized scale.

We then proceeded to test the scale's psychometric properties. The scale consistently showed strong construct and convergent validity—we consistently obtained a single, reliable factor, and the instrument typically yielded strong associations with several other measures of religiosity. Moreover, the scale demonstrated exceptional utility, as it was typically the strongest unique predictor of a wide range of outcome measures including social attitudes (anti-atheist prejudice), attitudes toward social policy (beliefs about the cultural authority of science), and moral cognition including orientations toward deontological thinking and prohibitive moral rules. Finally, scale validity was demonstrated across multiple samples of U.S. religious believers (also nonbelievers in Study 2b) and one sample of Indian Hindus.

\section{MFDA, Social Attitudes, and Cultural-Evolutionary Theories of Religiosity}

Results consistently showed that Divine Command beliefs formed the strongest unique predictor of anti-atheist prejudice. Moreover, in Study 1a MFDA was associated with beliefs about atheists' moral traits more strongly than with beliefs about atheists' amoral traits. This provides novel support for the moral distrust hypothesis of anti-atheist prejudice, which posits that religious-based anti-atheist prejudice emerges chiefly from perceptions of atheist immorality, mediated through beliefs about divine punishment as a motivator of moral behavior (see Gervais et al., 2011). The present findings show for the first time that beliefs about God as moral authority (i.e., God as both the author of morality and the ultimate source of moral guidance) are central to anti-atheist prejudice, consistent with the theorizing of Gervais and colleagues. Our findings also support the notion that anti-atheist prejudice is focused on perceptions of atheists' immorality. In Study 1a, mean ratings of atheists' moral traits were the 
lowest ratings, and negative correlations between the MFDA and atheists' moral ratings were significantly larger than between the MFDA and other trait dimensions (e.g., competence, sociability).

The moral distrust theory of anti-atheist prejudice emerged from theories regarding the cultural-evolutionary origins of religious belief (e.g., Atran \& Henrich, 2010; Gervais et al., 2011; Norenzayan, 2013; Norenzayan et al., in press). These theories posit that the historical puzzle of how small, kin-based tribal groups expanded to become large-scale societies can be explained by the emergence of a shared belief in a moralizing, watchful, punitive deity. Such a belief is theorized to have allowed non-kin to cooperate with and trust one another, as moral transgressions and trust violations would have aroused concerns of supernatural punishment, whether in this life or the next (see also Johnson \& Bering, 2006). MFDA addresses this perspective better than any other measure we are aware of, as it measures not only one's belief in God, but also specifically a belief that God is the ultimate source of moral knowledge and instruction. Hence, this measure will likely be valuable in ongoing research. For example, experimental attempts to reduce anti-atheist prejudice-e.g., by priming participants with secular authority (Gervais \& Norenzayan, 2012) or increasing perceived atheist prevalence (Gervais, 2011) - may be less effective on individuals high in MFDA due to their strong conviction that morality depends on faith in God and knowledge of his laws.

\section{Conflicts between Religion and Science}

Religious and scientific explanations for worldly phenomena are often at odds (e.g., the Earth was either created in six days or it evolved over billions of years; Preston \& Epley, 2009). As a consequence, devout Biblical literalists are often antagonistic toward science (Gauchat, 2015). In the present study, Biblical literalism was indeed a significant unique predictor of 
attitudes toward science; however, we found MFDA to be a stronger predictor. This suggests that although generally held beliefs in the literal truth of the Bible are important in religious believers' attitudes toward science, beliefs about the divine foundations of morality are particularly relevant, as religious adherents may especially fear that secularism undermines the moral fabric of society. However, our current investigation into attitudes toward science was exploratory. We encourage further research into the role of Divine Command beliefs in attitudes toward science, using a wider and more nuanced range of measures.

\section{Moral Cognition}

Studies $2 \mathrm{a}-2 \mathrm{~b}$ shed light on how meta-ethical beliefs about the divine origins of morality shape aspects of moral cognition. In Study 2a we replicated past findings (Piazza \& Landy, 2013) regarding the role of meta-ethical beliefs in the inclination to engage in utilitarian moral thinking. Specifically, Divine Command beliefs were central in explaining why religious believers are relatively committed to moral rules in the face of utilitarian alternatives. Consistent with Piazza and Sousa's (2013) rationale, it would seem that religious individuals are often ruleoriented because they view moral rules as grounded in God's supreme moral authority.

In Study $2 b$ we extended these findings to another area of moral cognition - how strongly a person endorses prohibitive moral rules. MFDA significantly and uniquely predicted a prohibitive (but not a prescriptive) moral orientation. We hypothesized this would be the case because Divine Commands are typically framed as prohibitions (e.g., "Thou shalt not kill”) rather than prescriptions (e.g., "Thou shall strive to save lives"). While the present study found support for this idea, religious belief was also associated, to some extent, with a prescriptive moral orientation. Future research should continue examining the relationship between religion and moral orientations using other measures (e.g., see Janoff-Bulman et al., 2009). We 
anticipate that the MFDA scale will be useful in assessing religious-grounded meta-ethical beliefs as they relate to a number of moral cognitive outcomes, including the degree to which people view moral propositions to be (a) objectively true, (b) universally applicable, and (c) unchangeable by human authority.

\section{Conclusion}

As religiosity continues to gain more and more attention in the social and personality sciences, it is important that researchers are able to address and statistically measure the full range of dimensions on which religious believers might vary. Pragmatism is also important, as researchers often face several practical impediments to their research questions such as time allowances and concerns for participant fatigue and attention span, all of which impede the ability to juxtapose certain constructs against others when testing hypotheses. In establishing, validating, and demonstrating the utility of a shortened, 5-item measure of Divine Command beliefs, we hope that the present work will facilitate ongoing research into religiosity, moral psychology, and how the two intersect. 


\section{FOOTNOTES}

1. These were: moral, honest, trustworthy, fair, compassionate, and respectful (Morality traits), sociable, friendly, extroverted, cooperative, and enthusiastic (Sociability traits), competent, effective, talented, and dynamic (Competence traits), and humble, principled, responsible, and disciplined (Moral-competence traits). Landy et al. (in preparation) used pre-ratings of the relevance of each trait for measuring the three underlying dimensions of morality, competence, and sociability, and the combined moral-competence factor.

2. An EFA suggested a single factor structure as a first factor yielded an eigenvalue of 13.29 and explained $69.95 \%$ of variance; a second factor explained only $5.76 \%$ of variance, eigenvalue $=1.10$ (all other eigenvalues <.58). This suggests than a general antipathy toward atheists is driving responses to each item. We proceeded to distinguish items based on conceptual criteria (see Footnote 2), since a previous study by Landy et al. (in preparation), from which the traits were derived, found a theoretically-meaningful threefactor structure (morality, competence, sociability) using a similar set of traits with a much wider cast of social targets.

3. We discuss results from models that included several covariates. We note that MFDA also emerged as the strongest predictor in all models that included only a single covariate. 


\section{REFERENCES}

Antonenko Young, O., Willer, R., \& Keltner, D. (2013). “Thou shalt not kill”: Religious fundamentalism, conservatism, and rule-based moral processing. Psychology of Religion and Spirituality, 5, 110-115.

Brown, T.A. (2015). Confirmatory Factor Analysis for Applied Research (2 $2^{\text {nd }}$ edition). New York: Guilford Press.

Edgell, P., Gerteis, J., \& Hartmann, D. (2006). Atheists as “other”: Moral boundaries and cultural membership in American society. American Sociological Review, 71, $211-234$.

Gauchat, G. (2015). The Political Context of Science in the United States: Public Acceptance of Evidence-Based Policy and Science Funding. Social Forces: sov040v1-sov040.

Gervais, W.M. (2011). Finding the faithless: Perceived atheist prevalence reduce anti-atheist prejudice. Personality and Social Psychology Bulletin, 37, 543-556.

Gervais, W.M. (2013). In Godlessness we distrust: Using social psychology to solve the puzzle of anti-atheist prejudice. Social and Personality Psychology Compass, 7, 366-377.

Gervais, W.M., \& Norenzayan, A. (2012). Reminders of secular authority reduce believers' distrust of atheists. Psychological Science, 23, 483-491.

Gervais, W.M., Shariff, A.F., \& Norenzayan, A. (2011). Do you believe in atheists? Distrust is central to anti-atheist prejudice. Journal of Personality and Social Psychology, 101, 1189-1206.

Ginges, J., Hansen, I.G., \& Norenzayan, A. (2009). Religion and support for suicide attacks. Psychological Science, 20, 224-230.

Goodwin, G.P., \& Darley, J.M. (2008). The psychology of meta-ethics: Exploring objectivism. 
Cognition, 106, 1339-1366.

Graham, J., \& Haidt, J. (2010). Beyond beliefs: Religions bind individuals into moral communities. Personality and Social Psychology Review, 14(1), 140-150. e50092.

Graham, J., Nosek, B.A., Haidt, J., Iyer, R., Koleva, S., \& Ditto, P.H. (2011). Mapping the moral domain. Journal of personality and social psychology,101(2), 366.

Hughes, J., Grossmann, I., \& Cohen, A.B. (2015). Tolerating the “doubting Thomas”: How centrality of religious beliefs vs. practices influences prejudice against atheists. Frontiers in psychology, 6 .

Janoff-Bulman, R., Sheikh, S., \& Hepp, S. (2009). Proscriptive versus prescriptive morality: Two faces of moral regulation. Journal of Personality and Social Psychology, 96(3), 521537.

Johnson, D.D.P., \& Bering, J.M. (2006). Hand of God, mind of man: Punishment and cognition in the evolution of cooperation. Evolutionary Psychology, 4, 219-233.

Koenig, H.G., \& Büssing, A. (2010). The Duke University Religion Index (DUREL): A fiveitem measure for use in epidemiological studies. Religions, 1, 78-85.

Lee, I.A., \& Preacher, K.J. (2013, September). Calculation for the test of the difference between two dependent correlations with one variable in common [Computer software]. Available from http://quantpsy.org.

Norenzayan, A. (2013). Big Gods: How Religion Transformed Cooperation and Conflict. Princeton University Press.

Norenzayan, A., Shariff, A.F., Gervais, W.M., Willard, A., McNamara, R., Slingerland, E., 
BELIEF IN DIVINE MORAL AUTHORITY

\& Henrich, J. (in press). The Cultural Evolution of Prosocial Religions. Behavioral and Brain Sciences.

Pew Research Center (2014). Worldwide, Many See Belief in God as Essential to Morality. (www.pewglobal.org/files/2014/03/Pew-Research-Center- Global-Attitudes-ProjectBelief-in-God-Report-FINAL- March-13-2014.pdf).

Piazza, J. (2012). "If you love me keep my commandments": Religiosity increases preference for rule-based moral arguments. International Journal for the Psychology of Religion, 22, 285-302.

Piazza, J., \& Landy, J. (2013). "Lean not on your own understanding": belief that morality is founded on divine authority and non-utilitarian moral thinking. Judgment and Decision Making, 8(6), 639-661.

Piazza, J., \& Sousa, P. (2013). Religiosity, political orientation, and consequentialist moral thinking. Social Psychological and Personality Science, 5(3), 334-342.

Preston, J., \& Epley, N. (2005). Explanations versus applications: The explanatory power of valuable beliefs. Psychological Science, 16(10), 826-832.

Preston, J., \& Epley, N. (2009). Science and God: An automatic opposition between ultimate explanations. Journal of Experimental Social Psychology, 45, 238-241.

Shariff, A.F., Piazza, J., \& Kramer, S.R. (2014). Morality and the religious mind: Why theists and nontheists differ. Trends in Cognitive Sciences, 18(9), 439-441.

Sinnott-Armstrong, W. (2009). Morality: Without God? New York: Oxford University Press.

Zakrisson, I. (2005). Construction of a short version of the Right-Wing Authoritarianism (RWA) scale. Personality and Individual Differences, 39(5), 863-872. 


\section{ACKNOWLEDGMENTS}

We thank Lina Himawan for assistance with data analysis, and Azim Shariff for helpful correspondence and assistance developing the stimuli for Study $2 \mathrm{~b}$. 


\section{Appendix A}

Measure of Prohibitive and Prescriptive Moral Orientations from Study $2 b$

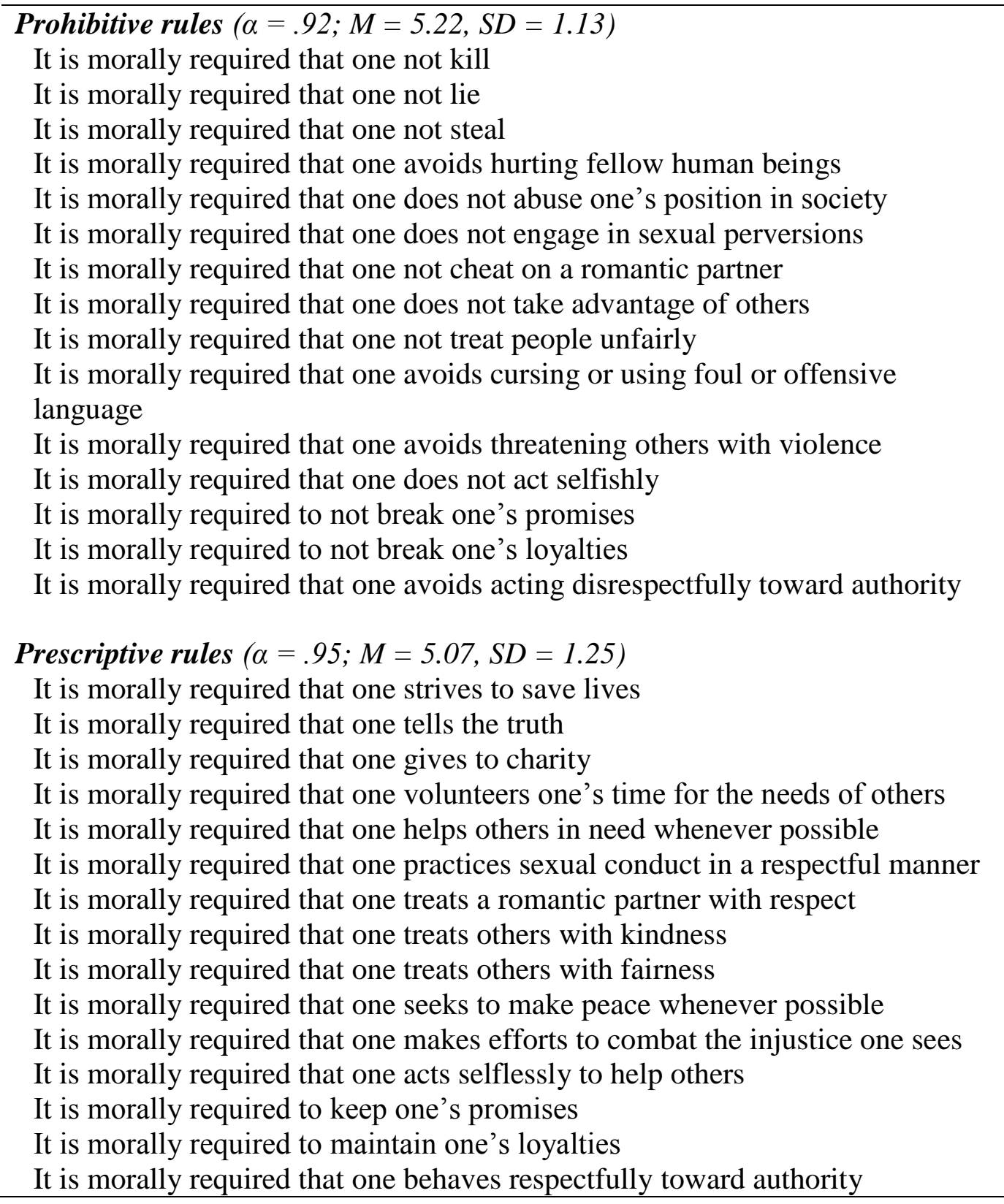

